\title{
Correlation of Women's Marital and Sexual Satisfaction in Different Family Life Cycle Stages in Khorram Abad, Iran
}

\author{
Masoumeh Fallah $^{1}{ }^{\mathbb{D}}$, Marzieh Saei Ghare Naz $^{1}$, Giti Ozgoli $^{2^{*}}{ }^{\mathbb{D}}$, Yadollah Mehrabi $^{3}$, Farnaz Farnam ${ }^{4}$, \\ Maryam Bakhtyari ${ }^{5}$
}

\begin{abstract}
Objectives: According to previous researches marital satisfaction has various patterns during family life cycle; meanwhile, there are only few studies showing a correlation between sexual and marital satisfaction in different stages of family life cycle. Therefore, the current study was designed to assess long-term female marital and sexual satisfaction in intimate relationships

Materials and Methods: In this cross-sectional study, 266 married women in different stages of their life family cycle recruited in the study through cluster random sampling technique. Outcomes measurement was carried out using three questionnaires: demographic, ENRICH marital satisfaction, and Larson sexual satisfaction.

Results: In this study, $24.4 \%$ of the women reported a high level of marital satisfaction while about $21.8 \%$ of them mentioned high levels of sexual satisfaction. Positive and highly significant correlation was observed between sexual and marital satisfaction in the first three stages of family life cycle (beginning a family $(\mathrm{r}=0.5, P=0.001)$, childbearing family $(\mathrm{r}=0.46, P=0.004)$, and families with preschool children $(\mathrm{r}=0.24, P=0.036)$. That is, both of the above-mentioned factors decreased slightly, however, such a correlation was not observed in the following stages $(P>0.05)$. In addition, it was found that, in the last 3 stages (i.e., teenage, empty nest, and retirement), despite a decrease in sexual satisfaction, marital satisfaction increased.

Conclusions: In general, the findings revealed that the correlation between sexual satisfaction and marital satisfaction reduced across the stages of life cycle. It seems that through deepening the relationship between the couples, other factors that are more important than sexual satisfaction would contribute to marital satisfaction as well.

Keywords: Women, Sexual satisfaction, Marital relationship
\end{abstract}

\section{Introduction}

The family life cycle indicates the developmental processes of family members (1). Duvall classified family cycle into the following stages: beginning families (I), families who are first time childbearing (II), those who have preschool children (III), families with school children (IV), those with teenagers $(\mathrm{V})$, families with their first child gone to last child's leaving home (VI), and families who have in the middle years (VII) (2). Meanwhile, Rollins and Feldman also believed that the couples' relationships were influenced by different stages of the family life cycle (3).

Marital satisfaction was defined as the happiness on different aspects of marital relationship $(4,5)$. Lawrance and Byers defined sexual satisfaction as "an effective response arising from one's subjective evaluation of the positive and negative dimensions associated with one's sexual relationship" (4).

Researches showed different patterns for marital satisfaction of the couples in the stages of family life cycle. For example, Lupri and Frideres obtained a U-shaped pattern which meant a decrease in marital satisfaction in the middle stages of life (5); however, Spanier et al reported curvilinear as well as negative linear trends; no relationship was found at all in three different samples between marital satisfaction and the stages of family life cycle (6).

According to some studies, sexual relationship is an important factor in marital satisfaction of the couples (7, 8). People usually judge about sexual satisfaction based on their marital satisfaction (9). Besides, it is believed that the concept of sexual satisfaction is intricately intertwined with marital satisfaction (10). Despite the existence of different patterns between marital satisfaction and stages of family life cycle, there already exist a correlation between sexual and marital satisfaction regardless of the stages of family life cycle $(7,8,10-15)$.In addition, sexual

Received 28 November 2017, Accepted 30 January 2018, Available online 14 February 2018

${ }^{1}$ Student Research Committee, School of Nursing \& Midwifery, Shahid Beheshti University of Medical Sciences, Tehran, Iran. ${ }^{2}$ Department of Midwifery and Reproductive Health, School of Nursing and Midwifery, Shahid Beheshti University of Medical Sciences, Tehran, Iran. ${ }^{3}$ Department of Epidemiology, School of Health \& Safety University of Medical Sciences, Tehran, Iran. ${ }^{4}$ Department of Reproductive Health, School of Nursing and Midwifery, Tehran University of Medical Sciences, Tehran, Iran. ${ }^{5}$ Department of Clinical Psychology, Faculty of Medicine, Shahid Beheshti University of Medical Sciences, Tehran, Iran.

*Corresponding Author: Giti Ozgoli, Tel: +982188202512, Emails: g.ozgoli@gmail.com \& gozgoli@sbmu.ac.ir 
and marital satisfaction influence marital stability (16).

In Iran, different studies showed that women's age was negatively correlated with their sexual satisfaction, that is, an increase in the age of women in family life cycle led to a decrease in sexual satisfaction. However, as it is pointed out, marital satisfaction had a U-shaped trend during the family life cycle (17). A different study conducted regarding marital and sexual satisfaction in a different part of the world but a few studies that examine the correlation between marital satisfaction and sexual satisfaction in women in different stages of family life cycle. Therefore, in this study attempts have been made to determine the pattern of sexual satisfaction in different stages of family life cycle as well as its correlation with marital satisfaction in each stage.

The researchers hypothesized that marital and sexual satisfaction had U-curved and decreasing trends in family life cycle, respectively. The aim of this study was to assess long-term female marital and sexual satisfaction in intimate relationships.

\section{Materials and Methods}

\section{Participants}

In this cross-sectional study, the participants were randomly selected from 6 health care centers in Khoram Abad (from July 2015 to June 2016). The cluster random sampling technique was used to recruit the samples. Overall, 266 women participated in this study. The stages of VII and VIII were integrated together so the family life cycle in this study were as: (I) beginning family, (II) childbearing family, (III) families with preschool age children, (IV) families with school-age children, (V) families with teenager, (VI) families as launching centers, and (VII) aging families.

\section{Procedure}

The privacy and confidentiality of data collection and analysis were explained to the samples. The inclusion criteria were women aged 18 year or older, being married, having passed 42 days postpartum, non-pregnant, married only once, the one who is her husband's only wife, living with the husband, and is literate. Exclusion criteria were suffering from active incurable diseases such as cancer, the history of stillbirth, abortion, or death of a child, active chronic mental illnesses, primary and secondary infertility, and also unwillingness to participate in this study.

The demographic data form consisted of eight questions as the woman's age, husband's age, marriage age, the age of children, education level, occupation, number of children, and family income.

The ENRICH marital satisfaction inventory consisted of four subscales and 35 items for assessing marital satisfaction. The validity and reliability of this research instrument has previously been confirmed (18). According to the study by Asoodeh et al, this scale was a valid and reliable scale in Iran as well (19). For the purpose of comparability of the scales, the scores of both questionnaires were transformed so that the maximum score was set to be 100 . This tool had a 5-point Likert-type scale with the following cut-off point: scores between 10$22(5 \%-15 \%)$ and $23-28(20 \%-35 \%)$ represented the strong low satisfaction and the low satisfaction dissatisfaction of marital partners, respectively. Moreover, scores between 29-35 (40\%-60\%) and 36-40 (65\%-80\%) indicated moderate satisfaction and high satisfaction, respectively. Finally, scores between 41-50 (85\%-100\%) showed a strongly high level of satisfaction.

Asoudeh reported the Alpha coefficients of 0.62, 0.78, $0.78,0.77$ for marital satisfaction, communication, conflict resolution, and idealistic distortion, respectively (20).

In addition, the Larson sexual satisfaction questionnaire (LSSQ) had 3 subscales including 25 items. Bahrami et al assessed the validity and reliability of his tool in Iran using the Cronbach a coefficient for all the items as above $(r=0.70)(21)$. This research instrument included a 5-point Likert-type scale with the following scores: between 25-50 (20\%-40\%) indicated dissatisfaction; and between 51-75 (41\%-60\%) denoted low satisfaction; besides, scores between 76-100 (61\%-80\%) indicated moderate satisfaction while scores between 100-125 (81\%-100\%) demonstrated high satisfaction (22).

Descriptive and inferential statistics were used for data analysis applying SPSS (statistical package for the social sciences) software, version 21. Descriptive statistics including frequency, mean, and standard deviation were employed to express the sample characteristics. The $P$-value $<0.05$ was considered statistically significant.

\section{Results}

The mean \pm SD age of the women in different stages were as follows: stage I) $\mathrm{M} \pm \mathrm{SD}=28.11 \pm 3.68$ years; stage II) $\mathrm{M} \pm \mathrm{SD}=26.59 \pm 3.84$; stage III) $\mathrm{M} \pm \mathrm{SD}=30.74 \pm 4.24$; stage IV) $\mathrm{M} \pm \mathrm{SD}=31.95 \pm 3.23$; stage $\mathrm{V}) \mathrm{M} \pm \mathrm{SD}=39.89 \pm 3.56$; and stage VI) $\mathrm{M} \pm \mathrm{SD}=51.95 \pm 3.43$. In the last stage of the family life cycle, it was $\mathrm{M} \pm \mathrm{SD}=62.84 \pm 4.15$ year. Table 1 shows the socio-demographic characteristics of the women in this study. Table 2 represents the mean \pm $\mathrm{SD}$ of sexual and marital satisfaction of the women in the different stages of family life cycle.

Across all the stages of family life cycle, about $28.6 \%$ of the women had low sexual satisfaction while $49.6 \%$ of them had moderate satisfaction; in addition, around $21.8 \%$ of the women indicated high sexual satisfaction. With regard to marital satisfaction, about $13.2 \%$ of the women had low marital satisfaction while $28.2 \%$ of them had moderate marital satisfaction; besides, totally, $24.4 \%$ of the women had high marital satisfaction while $34.2 \%$ of them indicated high strong marital satisfaction.

The maximum and minimum sexual satisfaction scores $(\operatorname{Max}=85.9$ \& Min $=56.5)$ were observed in stages I and $\mathrm{V}$, respectively. Furthermore, the highest and the lowest 
Table 1. Sociodemographic Characteristics of Women

\begin{tabular}{ll}
\hline Variables & Satisfaction \\
\hline Age $(y)^{\mathrm{a}}$ & $38.8 \pm 13.2$ \\
Age of spouse $(\mathrm{y})^{\mathrm{a}}$ & $42.7 \pm 13.9$ \\
${\text { Marriage age }(\mathrm{y})^{\mathrm{a}}}^{\mathrm{a}}$ & $26.1 \pm 3.8$ \\
${\text { Marriage duration }(\mathrm{y})^{\mathrm{a}}}^{\text {Education level }}$ & \\
Illiterate $^{\mathrm{b}}$ & $16.6 \pm 15.2$ \\
6-8 Grade & $31(11.7)$ \\
High school \& diploma & $51(19.2)$ \\
Academic & $81(30.5)$ \\
Employment status & $103(38.6)$ \\
Housewife & $173(65)$ \\
Employed & $81(30.5)$ \\
Retired & $12(4.5)$ \\
Economic status & \\
Good & $60(22.6)$ \\
Intermediate & $161(60.6)$ \\
Poor & $45(16.8)$ \\
\hline
\end{tabular}

${ }^{\mathrm{a}}$ Data are presented as mean $\pm \mathrm{SD}$; ${ }^{\mathrm{b}}$ Data are presented as No. (\%).

Table 2. The Mean \pm SD of Marital Satisfaction and Sexual Satisfaction in Different Stage of Family Life Cycle

\begin{tabular}{lcc}
\hline Stage of Family Life Cycle & Marital Satisfaction & Sexual Satisfaction \\
\hline I & $78.2 \pm 10.36$ & $85.9 \pm 6.95$ \\
II & $68.3 \pm 10.26$ & $72.6 \pm 8.82$ \\
III & $67.6 \pm 10.57$ & $72.6 \pm 9.79$ \\
IV & $58.8 \pm 10.59$ & $71.5 \pm 10.23$ \\
V & $83 \pm 7.17$ & $56.5 \pm 8.36$ \\
VI & $75.4 \pm 10.4$ & $61 \pm 6.91$ \\
VII & $85.3 \pm 7.14$ & $62.2 \pm 6.60$ \\
\hline
\end{tabular}

Data are presented as mean \pm SD.

levels of sexual satisfaction were observed in the age range of $21-30$ years $(76.3 \%)$ and $41-50$ years $(60.8 \%)$, respectively. Generally, sexual satisfaction's trend was decreased during family life cycle.

Besides, the maximum and minimum marital satisfaction scores were in stages of VII and IV (Max $=85.3$ $\&$ Min $=58.8)$, respectively. Marital satisfaction scores in the age range of 61-70 years were the highest $(\operatorname{Max}=84.5)$ while being the lowest in the age range of 31-40 years . Marital satisfaction showed a biphasic chart indicating a reduction from stage $\mathrm{I}$ to $\mathrm{V}$ and then again showed an increase in this regard.

According to Figure 1, in stages I to IV, the scores of sexual satisfaction were higher than those of marital satisfaction. However, this trend was reverse in stages $\mathrm{V}$ to VII. The Spearman correlation test showed a statistically significant relationship between marital and sexual satisfaction in the whole family life cycle $(P<0.001)$. Positive correlations were also reported between sexual and marital satisfaction in stages I, II, and III. However, in

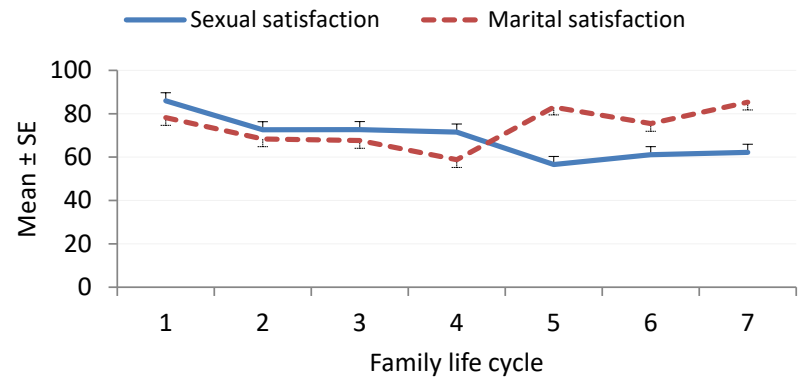

Figure 1. The Means Scores of Sexual and Marital Satisfaction of the Women in Each Stage of Family Life Cycle.

stages IV to VII, a non-significant and reducing trend of correlations were found (Table 3).

\section{Discussion}

The results of the present study indicated that during the first stage of family life cycle, i.e., familiarity or engagement stages when families had no children, high levels of sexual and marital satisfaction were observed so that the highest sexual satisfaction was reported by women with no child. Marital and sexual satisfaction and the number of year the couples spent together were related together (23). Based on the existing evidence, the higher sexual satisfaction at the beginning of marriage was due to its freshness $(24,25)$. According to Basson's sexual response cycle (26), greater sexual satisfaction during this period when the couple just took their spousal roles could lead to a more intimate marital relationship and consequently to a higher level of satisfaction. Sexual and relationship satisfaction were associated with each other (10) and generally, relationship duration of the couples had non-linear effect on their sexual satisfaction (24).

As it has been stated, when the first child was born, satisfaction reduced in both husband and wife. The lowest marital satisfaction was reported in families with an elementary school child. In other words, having a child negatively affected sexual and marital satisfaction. This is in line with the findings of the current study. In first-time, parents' low sexual satisfaction was due to the low marital satisfaction but this negative effect gradually decreased by high intimacy of the couples (27).

Leavitt et al demonstrated that in a shift to parental

Table 3. The Correlation Between Sexual Satisfaction and Marital Satisfaction

\begin{tabular}{lcc}
\hline Stage of Family Life Cycle & R & $\boldsymbol{P}$ Value \\
\hline I & 0.527 & 0.001 \\
II & 0.46 & 0.004 \\
III & 0.341 & 0.036 \\
IV & 0.295 & 0.065 \\
V & 0.107 & 0.529 \\
VI & 0.139 & 0.404 \\
VII & 0.122 & 0.467 \\
\hline
\end{tabular}


stage caused stress in the couple resulting in reduced sexual satisfaction (28). A meta-analytical study by Dillon and Beechler also reflected that the number of children had a negative effect on marital satisfaction (29). Evidence showed that marital satisfaction in middle-aged couples who had high level of nontangible supports from adult children was high (30). Moreover, couples communication was found to affect their sexual satisfaction (31).

This finding can be interpreted as follows: increased parenting-related stress, less time dedicated to each other due to the child's demands, greater engagement and reduced relationship between husband and wife, more parental responsibilities, and failure to divide the household chores and labor (32) which caused lower sexual and marital satisfaction at this stage of family life cycle. According to the findings, as children reached their adolescence, a more decrease in sexual satisfaction and a relative increase in marital satisfaction were achieved. In the present study, the lowest degree of sexual satisfaction was observed among women with adolescent children. Regarding the decreasing trend of sexual satisfaction at this stage and its persistence through the next stage, it is likely that the loss of freshness as well as monotony of sexual life lead to reduced sexual satisfaction due to lack of necessary skills to protect and promote it. Inconsistent with the findings of the present study, Hirschberger et al concluded that with the birth of the first baby to his/ her adolescence (15 years old), the degree of sexual satisfaction would decrease (33). A number of studies have reported that maturity and its relevant changes in adolescents led to lower marital satisfaction in their parents $(34,35)$. However, the results of the current study demonstrated a relative increase in marital satisfaction compared to the previous stages which might be due to the couple's enhanced experience in their parental and spousal roles or both that resulted in a relatively greater marital satisfaction. Through the final stages of family life cycle, marital satisfaction improved, although sexual satisfaction was still declining so that the highest marital satisfaction occurred during the empty nest stage. Furthermore, Gorchoff et al in their study indicated that during the empty nest stage when children leave their parents' house, the couples experience a higher level of marital satisfaction (36). Abbasi et al also reported that the highest degree of marital satisfaction was observed during the first stages of family life cycle (newly married and without any children) as well as the final stages of this cycle (empty nest) (17). The number of children was also found to have an effect on marital satisfaction and sexual satisfaction of the couples $(37,38)$.

In order to provide a justification for the low level of sexual satisfaction in the present study, it can be stated that as the previous stages, monotony of sexual life resulted in reduced sexual satisfaction. However, with a deepened marital relationship over long and continued years, marital satisfaction was affected by non-sexual factors such as playing spousal or maternal roles (39) which were more important than sexual satisfaction. Therefore, marital satisfaction was raised at this stage despite a reduced sexual satisfaction. The findings of the present research indicated that about $87 \%$ of people had a good (high and very high) marital satisfaction over different stages of life and one third of them enjoyed a really high level of satisfaction. In addition, about half of the people had an average sexual satisfaction and no one was found without any sexual satisfaction. Although some women did not have a high sexual satisfaction, their marital satisfaction was high. According to the available evidence, it can be claimed that undertaking maternal and spousal roles may cause marital satisfaction (39). As a result, marital satisfaction would increase despite low level of sexual satisfaction. Meanwhile, on one hand, evidence suggested that some Iranian women considered satisfaction with sexual relationship as being loved by their spouse so that they were satisfied if they would perceive this non-sexually (40). On the other hand, as the women under study had a stable marital relationship and this relationship was stable in more satisfied couples, marital satisfaction was high in more than four-fifth of the samples.

The purpose of this study was to describe the state of volatility of sexual and marital satisfaction in different stages of life. This description of the status may be important for the couples' awareness raising during their marriage considering that these changes are a natural part of their marital life and that such reductions in marital satisfaction may not be disturbing. The purpose of this study was not to explain the causes of different trends among couples in all the stages in particular; however, it should be noted that many factors affect marital and sexual satisfaction in the long lives so it is recommended to assess these factors in future studies.

\section{Conclusions}

In the current study, women with marital stability, through which different stages of child development were gone, had a good marital satisfaction and an average sexual satisfaction in most cases; no individual was found without any sexual satisfaction and even low sexual satisfaction during the following stages did not lead to low marital satisfaction. Consequently, it seems that nonsexual factors were more significant than sexual satisfaction in this respect and that their identification is subject to further investigation. Besides, intervention programs are proposed in order to enhance sexual satisfaction among women in their latter stages of family life cycle.

\section{Limitations of the Study}

Although self-report questionnaires were completed by the participants, they may not be completed carefully owing to a socio-cultural taboo. In addition, this study was only conducted in Khorram Abad, and thus the results may not be generalized to all the other Iranian cities since 
other contexts may yield different results.

\section{Conflict of Interests}

Authors declare that they have no conflict of interests.

\section{Ethical Issues}

Human subjects' protection approval for the research was obtained from Lorestan Medical University of Institutional Review Board (with the ethical code of LUMS.REC.1394, 5) and Shahid Beheshti University of Medical Sciences, Tehran (ethical No. IR.SBMU.PHNM.1397.59). In addition, informed consent was obtained from all the participants.

\section{Financial Support}

None.

\section{Acknowledgments}

The authors would like to appreciate the vice-chancellor of research and technology affairs at Shahid Beheshti and Lorestan Universities of Medical Sciences and all the people who took part in this study.

\section{References}

1. McCarthy LA. Influences couple conflict type, division of labor, and violated expectations on first-time parent 's individual and marital well-being [dissertation]. Gainesville, Florida: University of Florida; 2006.

2. Duvall EM. Family Development. Philadelphia: Lippincott; 1967.

3. Rollins BC, Feldman H. Marital Satisfaction over the Family Life Cycle. J Marriage Fam. 1970;32(1):20-28. doi:10.2307/349967

4. Lawrance KA, Byers ES. Sexual satisfaction in long-term heterosexual relationships: The interpersonal exchange model of sexual satisfaction. Pers Relatsh. 1995;2(4):267285. doi:10.1111/j.1475-6811.1995.tb00092.x

5. Lupri E, Frideres J. The Quality of Marriage and the Passage of Time: Marital Satisfaction over the Family Life Cycle. Can J Sociol. 1981;6(3):283-305. doi:10.2307/3340235

6. Spanier GB, Lewis RA, Cole CL. Marital Adjustment over the Family Life Cycle: The Issue of Curvilinearity. J Marriage Fam. 1975;37(2):263-275. doi:10.2307/350960

7. Litzinger S, Gordon KC. Exploring relationships among communication, sexual satisfaction, and marital satisfaction. J Sex Marital Ther. 2005;31(5):409-424. doi:10.1080/00926230591006719

8. Guo B, Huang J. Marital and sexual satisfaction in Chinese families: exploring the moderating effects. J Sex Marital Ther. 2005;31(1):21-29. doi:10.1080/00926230590475224

9. Wenner CA. Is Sex Important to Marital Satisfaction or is Marital Satisfaction Important to Sex? Top-down and Bottom-up Processing in the Bedroom [Thesis]. Tennessee: University of Tennessee; 2010.

10. McNulty JK, Wenner CA, Fisher TD. Longitudinal Associations Among Relationship Satisfaction, Sexual Satisfaction, and Frequency of Sex in Early Marriage. Arch Sex Behav. 2016;45(1):85-97. doi:10.1007/s10508-014-

\section{4-6 6}

11. Karney BR, Bradbury TN. The longitudinal course of marital quality and stability: a review of theory, method, and research. Psychol Bull. 1995;118(1):3-34.

12. McNulty JK, Karney BR. Attributions in Marriage: Integrating Specific and Global Evaluations of a Relationship. Pers Soc Psychol Bull. 2001;27(8):943-955. doi:10.1177/0146167201278003

13. Gadassi R, Bar-Nahum LE, Newhouse S, et al. Perceived Partner Responsiveness Mediates the Association Between Sexual and Marital Satisfaction: A Daily Diary Study in Newlywed Couples. Arch Sex Behav. 2016;45(1):109-120. doi:10.1007/s10508-014-0448-2

14. Schoenfeld EA, Loving TJ, Pope MT, Huston TL, Stulhofer A. Does Sex Really Matter? Examining the Connections Between Spouses' Nonsexual Behaviors, Sexual Frequency, Sexual Satisfaction, and Marital Satisfaction. Arch Sex Behav. 2017;46(2):489-501. doi:10.1007/s10508-015-06724

15. Byers ES. Relationship satisfaction and sexual satisfaction: a longitudinal study of individuals in longterm relationships. J Sex Res. 2005;42(2):113-118. doi:10.1080/00224490509552264

16. Yeh HC, Lorenz FO, Wickrama KA, Conger RD, Elder GH, Jr. Relationships among sexual satisfaction, marital quality, and marital instability at midlife. J Fam Psychol. 2006;20(2):339-343. doi:10.1037/0893-3200.20.2.339

17. Abbasi M, Dehghani M, Mazaheri M, Ansarinejad F, Fadaie Z. Trend Analysis of Changes in Marital Satisfaction and Related Dimensions Across Family Life Cycle. Journal of Family Research. 2010;6(1):5-22. [Persian].

18. Fowers BJ, Olson DH. Enrich marital inventory: a discriminant validity and cross-validation assessment. J Marital Fam Ther. 1989;15(1):65-79. doi:10.1111/j.1752-0606.1989.tb00777.x

19. Asoodeh MH, Khalili S, Daneshpour M, Lavasani MG. Factors of successful marriage: Accounts from self described happy couples. Procedia Soc Behav Sci. 2010;5:2042-2046. doi:10.1016/j.sbspro.2010.07.410

20. Asoudeh M. Factors affecting successful marriages from successful couple's perspective [dissertation]. Tehran University: Tehran; 2010.

21. Bahrami N, Yaghoobzadeh A, Sharifnia H, Soliemani MA, Haghdoost AA. Validity and Reliability of the Persian Version of Larson sexual Satisfaction Questionnaire in Couples. Journal of Kerman University of Medical Sciences. 2016;23(3):344-356.

22. Larson JH, Anderson SM, Holman TB, Niemann BK. A longitudinal study of the effects of premarital communication, relationship stability, and self-esteem on sexual satisfaction in the first year of marriage. J Sex Marital Ther. 1998;24(3):193-206. doi:10.1080/00926239808404933

23. Heresi Milad E, Rivera Ottenberger D, Huepe Artigas D. Associations among attachment, sexuality, and marital satisfaction in adult Chilean couples: a linear hierarchical models analysis. J Sex Marital Ther. 2014;40(4):259-274. do i: 10.1080/0092623x.2012.756840

24. Schmiedeberg C, Schroder J. Does Sexual Satisfaction Change With Relationship Duration? Arch Sex Behav. 2016;45(1):99-107. doi:10.1007/s10508-015-0587-0 
25. Addis IB, Van Den Eeden SK, Wassel-Fyr CL, Vittinghoff E, Brown JS, Thom DH. Sexual activity and function in middleaged and older women. Obstet Gynecol. 2006;107(4):755764. doi:10.1097/01.AOG.0000202398.27428.e2

26. Basson R. The female sexual response: a different model. J Sex Marital Ther. 2000;26(1):51-65. doi:10.1080/009262300278641

27. Nezhad MZ, Goodarzi AM. Sexuality, intimacy, and marital satisfaction in Iranian first-time parents. J Sex Marital Ther. 2011;37(2):77-88. doi:10.1080/0092623x.2011.547336

28. Leavitt CE, McDaniel BT, Maas MK, Feinberg ME. Parenting Stress and Sexual Satisfaction Among First-time Parents: A Dyadic Approach. Sex Roles. 2017;76(5-6):346355. doi:10.1007/s11199-016-0623-0

29. Dillon LM, Beechler MP. Marital satisfaction and the impact of children in collectivist cultures: A meta-analysis. J Evol Psychol. 2010;8(1):7-22. doi:10.1556/jep.8.2010.1.3

30. Polenick CA, Birditt KS, Zarit SH. Parental Support of Adult Children and Middle-Aged Couples' Marital Satisfaction. Gerontologist. 2018;58(4):663-673. doi:10.1093/geront/ gnx021

31. Jones AC, Robinson WD, Seedall RB. The Role of Sexual Communication in Couples' Sexual Outcomes: A Dyadic Path Analysis. J Marital Fam Ther. 2017. doi:10.1111/ jmft.12282

32. Sanders KM. Marital Satisfaction Across the Transition to Parenthood [Thesis]. Lincoln: University of Nebraska; 2010.

33. Hirschberger G, Srivastava S, Marsh P, Cowan CP, Cowan PA. Attachment, Marital Satisfaction, and Divorce During the First Fifteen Years of Parenthood. Pers Relatsh.
2009;16(3):401-420. doi:10.1111/j.1475-6811.2009.01230.x

34. Whiteman SD, McHale SM, Crouter AC. Longitudinal Changes in Marital Relationships: The Role of Offspring's Pubertal Development. J Marriage Fam. 2007;69(4):10051020. doi:10.1111/j.1741-3737.2007.00427.x

35. Cui M, Donnellan MB. Trajectories of Conflict over Raising Adolescent Children and Marital Satisfaction. J Marriage Fam. 2009;71(3):478-494. doi:10.1111/j.17413737.2009.00614.x

36. Gorchoff SM, John OP, Helson R. Contextualizing change in marital satisfaction during middle age: an 18-year longitudinal study. Psychol Sci. 2008;19(11):1194-1200. doi:10.1111/j.1467-9280.2008.02222.x

37. Zaheri F, Dolatian M, Shariati M, Simbar M, Ebadi A, Azghadi SB. Effective Factors in Marital Satisfaction in Perspective of Iranian Women and Men: A systematic review. Electron Physician. 2016;8(12):3369-3377. doi:10.19082/3369

38. Bayoglu Tekin Y, Ural UM, Ustuner I, Balik G, Guvendag Guven ES. Evaluation of female sexual function index and associated factors among married women in North Eastern Black Sea region of Turkey. Turk J Obstet Gynecol. 2014;11(3):153-158. doi:10.4274/tjod.43815

39. Khamsehee A. relationship between sexual behavior and gender roles of married two groups of students: Comparison of Sexual Behavior of women and men in the family. Journal of family and Research. 2006;2(8):329-337. [Persian].

40. Mahdavi M, Nasimi M. A sociological Study of women, s satisfaction from the marital relationships. Journal of SOCIAL SCIENCES. 2008;2(3):5-27. [Persian].

(c) 2018 The Author (s); This is an open-access article distributed under the terms of the Creative Commons Attribution License (http://creativecommons.org/licenses/by/4.0), which permits unrestricted use, distribution, and reproduction in any medium, provided the original work is properly cited. 